\title{
Flow Distribution and Sediment Transport Mechanism in the Estuarine Systems of Ganges-Brahmaputra-Meghna Delta
}

\author{
Anisul Haque, Sumaiya, and Munsur Rahman
}

\begin{abstract}
The Ganges-Brahmaputra-Meghna delta is one of the most dynamic tide dominated deltas in the world, a dynamism forced in part by the huge flows and sediments generated in the catchments of the GBM basins. In this study, we apply 1D and 2D dynamic models (HEC RAS and Delft 3D) to analyze the volumetric flow distribution in these estuarine systems. The flow distribution parameters are then used as proxy variables to study the sediment transport mechanism in the region. Flow distribution patterns show that freshwater input and storage are much higher than the saltwater input and storage. Considering freshwater contribution, eastern estuarine system plays important role during monsoon whereas, during dry season it is central estuarine system. Western estuarine system mainly contributes to store saline water. The Lower Meghna estuary is the main flow and sediment carrying channel in the region. Clock-wise estuarine circulation makes the sediments to re-enter from the sea into central estuarine system, forms flocks in the saline environment, and cause sedimentation.
\end{abstract}

Index Terms-1D and 2D models, estuarine circulation, Ganges-Brahmaputra-Meghna delta, sediment transport.

\section{INTRODUCTION}

The Ganges-Brahmaputra-Meghna (GBM) delta is one of the most dynamic tide dominated deltas in the world. The flow generated in the upper catchment of the GBM basins is drained through the estuarine systems of the delta. This flow brings about 1 billion ton of sediment annually in this region [1] which is distributed by this estuarine systems. Although the main flow and sediment carrying channel is the Lower Meghna, there are numerous cross connecting channels in the South-West region of Bangladesh which carry some percentage of this flow and sediments. This region has diverse ecosystem [2] resources including the Sundarban Mangrove forest. The functioning of these ecosystem resources largely depends on water and sediment availability, which in turn is distributed by the complex estuarine networks of the region.

Considering the volume of freshwater and saltwater carried by these different estuaries of the system, the estuarine

Manuscript received November 19, 2014; revised May 5, 2015. The authors would like to acknowledge to NERC, ESRC, UK DFID, ESPA for funding this work as part of the ESPA Deltas project (Grant Reference Code NEJ0027551). We would like to acknowledge the contribution of all the members associated with the research team who has direct and indirect input to this article.

The authors are with the Institute of Water and Flood Management (IWFM), Bangladesh University of Engineering and Technology (BUET), Dhaka-1000, Bangladesh (e-mail: anisul@iwfm.buet.ac.bd, Sumaiyasunam@gmail.com,mmrahman@iwfm.buet.ac.bd). systems of the GBM delta is classified into three discrete systems, i.e., the Eastern Estuarine System (EES), the Central Estuarine System (CES) and the Western Estuarine System (WES) [3] as shown in Fig. 1.

Unfortunately, until now the available information is not adequate to have a detailed understanding of the flow \& sediment dynamics and flow \& sediment distribution patterns in these estuarine systems. Some [4]-[7] models have previously been applied to study the flow and transport. Among these models, the 1D model [4] studied the salinity intrusion in the Lower Meghna estuary, the other 1D model [5] studied the flood characteristics of the major rivers, 2D model [6] studied the circulation pattern in the Lower Meghna estuary, the other 2D model [3] studied the fluvial-tidal characteristics of the estuarine systems and the 3D model [7] studied the residual circulation pattern in the Lower Meghna estuary. None of these models focused on the volumetric flow analysis in these estuarine systems which are vital to understand the water resource availability. This water resource availability is essential for sustenance of ecosystem resources in the region. The relation between available water storage and sediment transport mechanism, which is also related to the estuarine circulation pattern, is unknown. These two aspects will be covered in this paper. The flow distribution parameters will be used as a proxy variable to understand the sediment transport mechanism. Isohalines of threshold salinity value, representing sustenance of ecosystem resources are used to demarcate the freshwater and saltwater zone. In doing this, a one dimensional numerical model (HEC RAS unsteady) and a two dimensional depth averaged flow and salinity model (Delft 3D) have been applied to analyze the flow distribution patterns of the estuarine systems of GBM delta. Particular emphasis is given on the seasonal flow distribution.

\section{APPLICATION OF THE MODELS}

The unsteady version of HEC RAS solves the St. Venant equations of mass and momentum conservation [8]. The numerical solution is performed by using an implicit finite difference method. The model can accommodate branching of river networks with multiple junctions. The model requires upstream and downstream boundary conditions and a detailed bathymetry of the river network. A time series of discharge has to be specified as the upstream boundary condition, with a time series of water level for the downstream boundary condition. On the other hand, the depth averaged version of the Delft 3D computes the depth averaged flow and salinity 
fields. The upstream boundaries are specified as measured discharges and downstream boundaries are specified as tidal water levels at the sea. For the salinity model, constant sea salinity of $35 \mathrm{ppt}$ for the Bay of Bengal is specified as sea boundary condition [9]. The bathymetries for both the models are specified from the cross sections measured under the ESPA Delta project. Sea bathymetry is provided from the Open access General Bathymetric Chart of the Oceans (GEBCO). For both the models measured discharges collected from Bangladesh Water Development Board (BWDB) at the major rivers, i.e., at the Ganges, Brahmaputra and Upper Meghna rivers are used as the upstream boundary conditions.

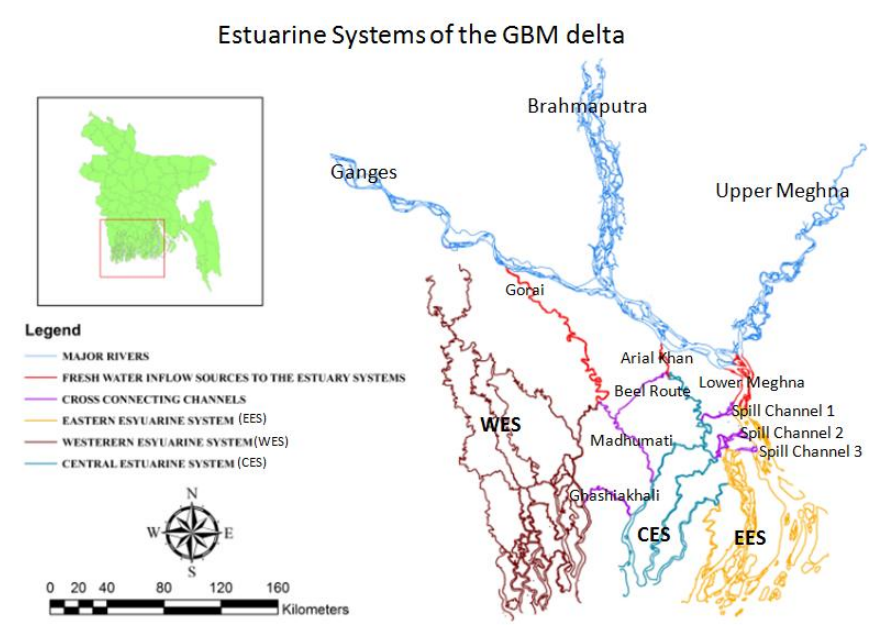

Fig. 1. Estuarine systems of the GBM delta.

As shown Fig. 1, the discharge coming from the GBM catchments come through the Ganges, the Brahmaputra and the Upper Meghna rivers and ultimately drain through the GBM estuarine systems. The main outlet of this flow is the Lower Meghna estuary. This flow also drains through two small outlets - the Gorai Rivers from the Ganges and the Arial

\section{Model validation: Lower Meghna}

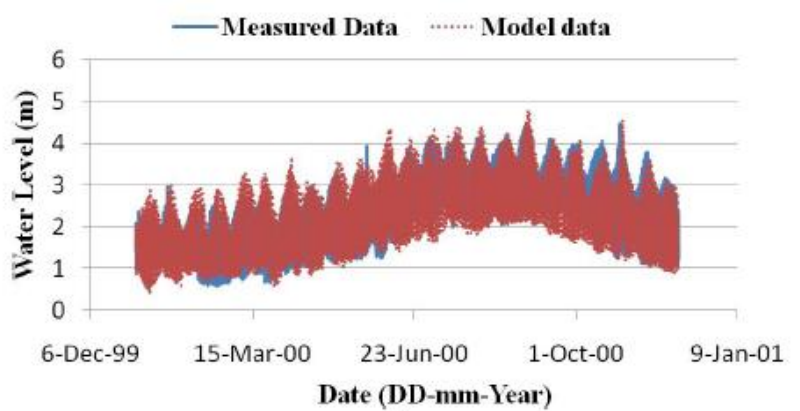

(a)

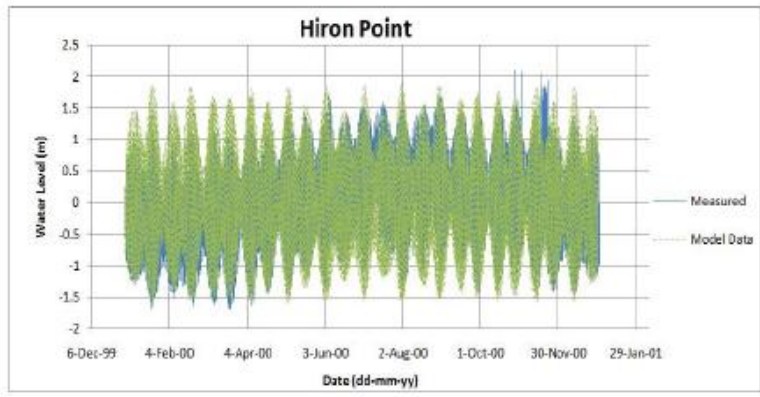

(c)
Khan from the Padma. After receiving water from these three outlets, the bulk of this flow drains through the Lower Meghna estuary to the Bay of Bengal. The Lower Meghna estuary, on its way to the Bay of Bengal, discharges through the three spill channels. These spill channels are the cross channels that connect EES with CES. The Lower Meghna, the Tetulia and the Lohalia along with the three spill channels form the EES. The main three estuaries of the CES are the Burishwar, Bishkhali and Baleswar. The Burishwar estuary comes out from the Tetulia estuary and drains directly to the Bay of Bengal. The Bishkhali estuary is bifurcated from the Tetulia estuary and drains directly to the Bay of Bengal. The Baleswar estuary, which is the widest among the estuaries in the zone, comes out principally from the Arial Khan River. The Gorai River is the only source of freshwater flow in the WES region. Among the cross channels apart from the three spill channels mentioned above, the Beel Route connects the EES \& CES and the Ghashiakhali \& Madhumati connect the CES and WES. The schematized river and estuarine network for both the HEC RAS and the Delft 3D models are shown in Fig. 2.

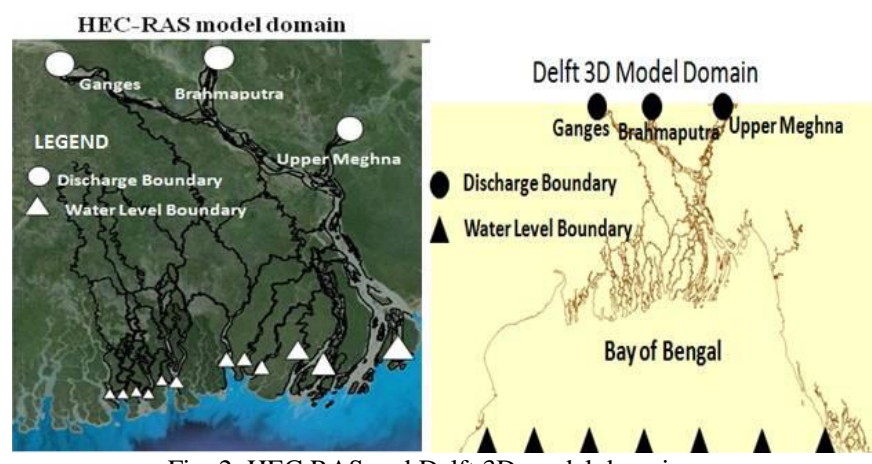

Fig. 2. HEC RAS and Delft 3D model domains.

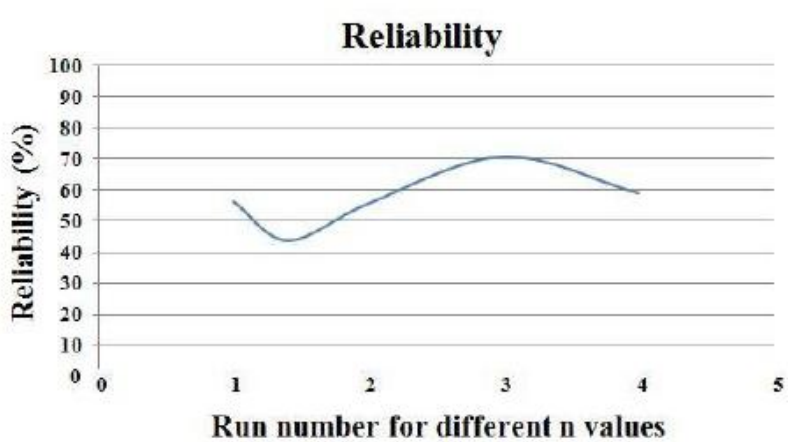

(b)

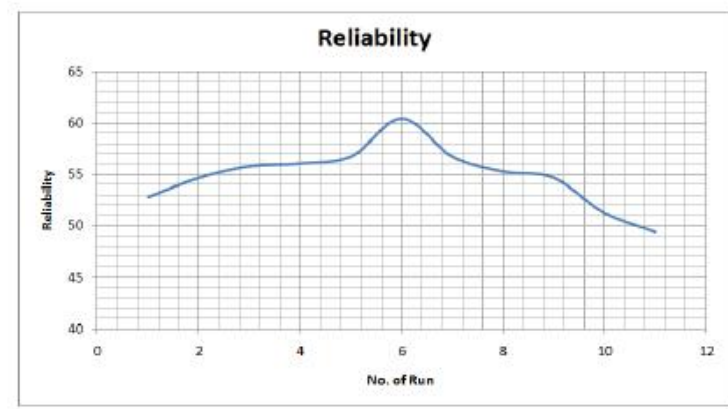

(d)

Fig. 3. (a) HEC-RAS model validation (b) HEC-RAS model calibration (c) Delft3D model validation (d) Delft3D model calibration. 


\section{Model CALIBRATION AND VALIDATION}

For selecting the bench mark for the model calibration and validation [10], an average flood year condition is selected. This will make the model capable of simulating both the normal and extreme events. In this case the year 2000 is selected as the average flood year based on the total percentage of area flooded in the country during that particular flood [11].

During the calibration exercise, model reliability is calculated for each of the model run by using the following [12]:

$$
\text { Reliability }=100-\frac{\frac{1}{n} \sum_{t=1}^{T}\left|W_{\text {Measured }}^{t}-W_{\text {Model }}^{t}\right|}{\sqrt{\frac{1}{n} \sum_{t=1}^{T}\left(W_{\text {Measured }}^{t}-\overline{W_{\text {Measured }}}\right)^{2}}} \times 100
$$

Here, Reliability is a new model reliability measure indicator introduced by [12] and is shown to quantify performance of a dynamic model realistically. Reliability = $100 \%$ means the model is $100 \%$ reliable. Here $W_{\text {Measured }}^{t}$ and $W_{\text {Model }}^{t}$ are the measured and the model values at any instant of time $t, \overline{W_{\text {Measured }}}$ is the average of the measured values, $t$ is any time instant, $T$ is total duration for both the measured and model values and $n$ is the total number of values.

For the model calibrations, different model runs are made by varying the Manning's roughness co-efficient ' $n$ '. Different roughness scenarios are made for the whole network. For each of the scenarios model reliabilities are calculated by using Equation (1) and the results are shown in Fig. 3 for both the HEC RAS and the Delft 3D models. The maximum reliability achieved for the HEC RAS model was around 70\% and the maximum reliability achieved for the Delft 3D model was around $60 \%$.

\section{SEASONAL Flow Distribution IN THE Estuarine SYSTEMS}

To simulate seasonal flow variation, three types of flooding scenarios are considered. These are 1) average flood year 2) wet year and 3) dry year. For each of the flood years the monsoon (May-October) and the dry season (November-April) are analyzed separately. Average flood year is defined as the flood year when $20 \%-24 \%$ of the entire country is flooded [11]. For any year if the country is flooded less than this amount is considered as dry year and for any year if the country is flooded more than this amount is considered as wet year [11]. According to these criteria, the year 2001 is considered as dry year ( $2.71 \%$ flooded), the year 2000 is considered as the average year $(24.19 \%$ flooded $)$ and the year 1998 is considered as the wet year (67.93\% flooded).

To compute the total flow volume in the GBM estuarine systems, the flow volumes of the estuaries of the EES, CES and WES are computed by integrating the discharge hydrographs using the following equation:

$$
V_{E_{i}}=\int_{0}^{T} Q d t
$$

where, $V_{E i}$ is the volume of water for a particular estuary $i, Q$ is the instantaneous discharge for that particular estuary and $T$ is the total duration of hydrograph. The total volume of water for the estuarine systems is calculated as:

$$
V_{T}=\sum_{i=1}^{N} V_{E_{i}}
$$

With the percentage distributions for each of the systems is calculated using:

$$
P=\frac{V_{E_{i}}}{V_{T}} \times 100
$$

where $V_{T}$ is the total volume of water for the system considered, $N$ is the number of estuaries for the particular system and $P$ is the percent contribution for each of the systems.

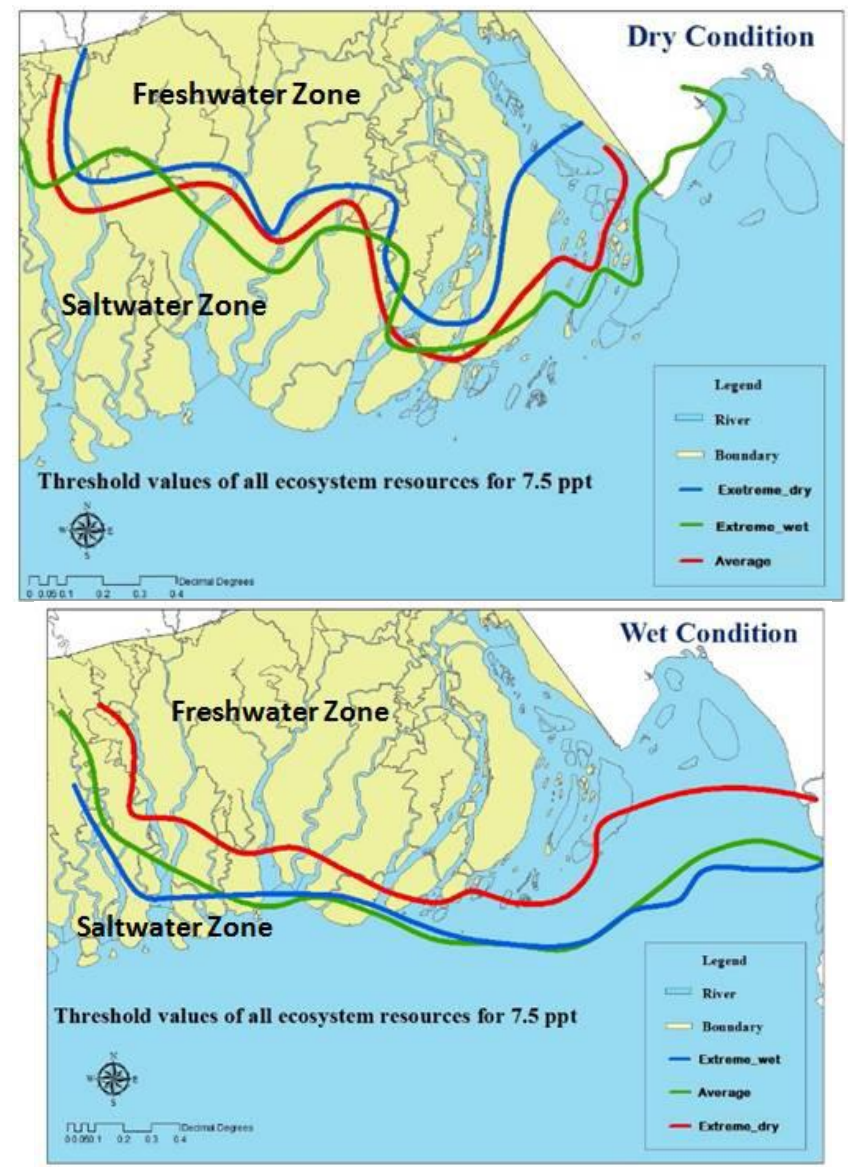

Fig. 4. Demarcation of freshwater-saltwater zone using the threshold isohaline: a) Dry condition b) Wet condition.

To compute the flow distribution in the estuarine systems, the entire estuarine network is divided as input and output systems. The input is considered as the flow contribution into the estuarine systems and the output is considered as the flow going out from the systems. The systems are again sub-divided into freshwater and saltwater zones. To 
demarcate the freshwater-saltwater interface, $7.5 \mathrm{ppt}$ isohaline is considered as the threshold limit. This limit is the salinity limit for the agriculture. Beyond this limit most of the agricultural crops will be affected by salinity [13]. This value is the lowest among the most common three ecosystem resources in the study area, i.e., agriculture $7.5 \mathrm{ppt}$, forestry 8 ppt [14] and fishery $10 \mathrm{ppt}$ [15]. The demarcation zones using this isohaline are shown in Fig. 4 for different flooding conditions and for wet $\&$ dry seasons. In Fig. 4, the region above the $7.5 \mathrm{ppt}$ isohaline is freshwater zone and the region below is the saltwater zone.

\begin{tabular}{|c|c|c|c|c|c|c|c|c|c|c|}
\hline \multirow{2}{*}{\multicolumn{3}{|c|}{ Flood Condition and seasonality }} & \multicolumn{2}{|c|}{$\begin{array}{c}\text { EES } \\
\left(\text { Trillion } \mathrm{m}^{3}\right)\end{array}$} & \multicolumn{2}{|c|}{$\begin{array}{c}\text { CES } \\
\left(\text { Trillion } \mathrm{m}^{3}\right)\end{array}$} & \multicolumn{2}{|c|}{$\begin{array}{c}\text { WES } \\
\left(\text { Trillion } \mathrm{m}^{3}\right)\end{array}$} & \multicolumn{2}{|c|}{$\begin{array}{c}\text { Total } \\
\left(\text { Trillion } \mathrm{m}^{3}\right)\end{array}$} \\
\hline & & & FWZ & SWZ & FWZ & SWZ & FWZ & SWZ & FWZ & SWZ \\
\hline \multirow{8}{*}{$\begin{array}{l}\text { Average } \\
\text { Year }\end{array}$} & \multirow{4}{*}{$\begin{array}{c}\text { Dry } \\
\text { season }\end{array}$} & Upstream input & 0.3 & 0 & 0.012 & 0.12 & 0.008 & 0.02 & 0.32 & 0.14 \\
\hline & & Downstream input & 0.65 & 0 & 0.021 & 0.04 & 0.02 & 0.3 & 0.691 & 0.34 \\
\hline & & Cross channel input & 0.03 & 0 & 0.32 & 0 & 0 & 0.005 & 0.35 & 0.005 \\
\hline & & Total input & 0.98 & 0 & 0.353 & 0.16 & 0.028 & 0.325 & 1.361 & 0.485 \\
\hline & \multirow{4}{*}{$\begin{array}{c}\text { Wet } \\
\text { season }\end{array}$} & Upstream input & 0.9 & 0 & 0.04 & 0 & 0.07 & 0.15 & 1.01 & 0.15 \\
\hline & & Downstream input & 0.6 & 0 & 0.03 & 0 & 0.12 & 0.3 & 0.75 & 0.3 \\
\hline & & Cross channel input & 0.04 & 0 & 0.5 & 0 & 0.001 & 0.0002 & 0.541 & 0.0002 \\
\hline & & Total input & 1.54 & 0 & 0.57 & 0 & 0.191 & 0.4502 & 2.301 & 0.4502 \\
\hline \multirow{8}{*}{$\begin{array}{l}\text { Wet } \\
\text { Year }\end{array}$} & \multirow{4}{*}{$\begin{array}{c}\text { Dry } \\
\text { season }\end{array}$} & Upstream input & 0.36 & 0 & 0.01 & 0.09 & 0.01 & 0.02 & 0.38 & 0.11 \\
\hline & & Downstream input & 0.72 & 0 & 0.04 & 0.09 & 0.02 & 0.1 & 0.78 & 0.19 \\
\hline & & Cross channel input & 0.36 & 0 & 0.28 & 0 & 0 & 0.002 & 0.64 & 0.002 \\
\hline & & Total input & 1.44 & 0 & 0.33 & 0.18 & 0.03 & 0.122 & 1.8 & 0.302 \\
\hline & \multirow{4}{*}{$\begin{array}{c}\text { Wet } \\
\text { season }\end{array}$} & Upstream input & 1.12 & 0 & 0.04 & 0 & 0.07 & 0.18 & 1.23 & 0.18 \\
\hline & & Downstream input & 0.47 & 0 & 0.09 & 0 & 0.15 & 0.36 & 0.71 & 0.36 \\
\hline & & Cross channel input & 0.03 & 0 & 0.4 & 0 & 0 & 0.004 & 0.43 & 0.004 \\
\hline & & Total input & 1.62 & 0 & 0.53 & 0 & 0.22 & 0.544 & 2.37 & 0.544 \\
\hline \multirow{8}{*}{$\begin{array}{l}\text { Dry } \\
\text { Year }\end{array}$} & \multirow{4}{*}{$\begin{array}{c}\text { Dry } \\
\text { season }\end{array}$} & Upstream input & 0.26 & 0.32 & 0.01 & 0.13 & 0.002 & 0.009 & 0.272 & 0.459 \\
\hline & & Downstream input & 0.07 & 0.96 & 0.06 & 0.09 & 0.01 & 0.3 & 0.14 & 1.35 \\
\hline & & Cross channel input & 0.04 & 0 & 0.37 & 0 & 0 & 0.003 & 0.41 & 0.003 \\
\hline & & Total input & 0.37 & 1.28 & 0.44 & 0.22 & 0.012 & 0.312 & 0.822 & 1.812 \\
\hline & \multirow{4}{*}{$\begin{array}{c}\text { Wet } \\
\text { season }\end{array}$} & Upstream input & 0.65 & 0 & 0.03 & 0 & 0.05 & 0.06 & 0.73 & 0.06 \\
\hline & & Downstream input & 0.69 & 0 & 0.1 & 0 & 0.06 & 0.32 & 0.85 & 0.32 \\
\hline & & Cross channel input & 0.03 & 0 & 0.3 & 0 & 0 & 0 & 0.33 & 0 \\
\hline & & Total input & 1.37 & 0 & 0.43 & 0 & 0.11 & 0.38 & 1.91 & 0.38 \\
\hline
\end{tabular}

\begin{tabular}{|c|c|c|c|c|c|c|c|c|c|c|}
\hline \multirow{2}{*}{\multicolumn{2}{|c|}{$\begin{array}{l}\text { Flood Condition } \\
\text { and seasonality }\end{array}$}} & \multirow{3}{*}{$\begin{array}{l}\text { Input, output } \\
\text { and storage of } \\
\text { water }\end{array}$} & \multirow{2}{*}{\multicolumn{2}{|c|}{$\begin{array}{c}\text { EES } \\
\left(\text { Trillion } \mathbf{~ m}^{3} \text { ) }\right. \\
\end{array}$}} & \multirow{2}{*}{\multicolumn{2}{|c|}{$\begin{array}{c}\text { CES } \\
\left(\text { Trillion } \mathbf{~ m}^{3}\right) \\
\end{array}$}} & \multirow{2}{*}{\multicolumn{2}{|c|}{$\begin{array}{c}\text { WES } \\
\left(\text { Trillion } \mathbf{m}^{3}\right) \\
\end{array}$}} & \multirow{2}{*}{\multicolumn{2}{|c|}{$\begin{array}{c}\text { Total } \\
\left(\text { Trillion } \mathbf{~ m}^{3}\right) \\
\end{array}$}} \\
\hline & & & & & & & & & & \\
\hline & & & FWZ & SWZ & FWZ & SWZ & FWZ & SWZ & FWZ & SWZ \\
\hline \multirow{6}{*}{$\begin{array}{l}\text { Average } \\
\text { Year }\end{array}$} & Dry & Total input & 0.98 & 0 & 0.353 & 0.16 & 0.028 & 0.325 & 1.361 & 0.485 \\
\hline & Season & Total output & 0.8 & 0 & 0.12 & 0.14 & 0.02 & 0.28 & 0.94 & 0.42 \\
\hline & & Storage & 0.18 & 0 & 0.233 & 0.02 & 0.008 & 0.045 & 0.421 & 0.065 \\
\hline & Wet & Total input & 1.54 & 0 & 0.57 & 0 & 0.191 & 0.4502 & 2.301 & 0.4502 \\
\hline & Season & Total output & 1.27 & 0 & 0.2 & 0 & 0.15 & 0.32 & 1.62 & 0.32 \\
\hline & & Storage & 0.27 & 0 & 0.37 & 0 & 0.041 & 0.1302 & 0.681 & 0.1302 \\
\hline \multirow{6}{*}{$\begin{array}{l}\text { Wet } \\
\text { Year }\end{array}$} & Dry & Total input & 1.44 & 0 & 0.33 & 0.18 & 0.03 & 0.122 & 1.8 & 0.302 \\
\hline & Season & Total output & 1 & 0 & 0.09 & 0.13 & 0.02 & 0.12 & 1.11 & 0.25 \\
\hline & & Storage & 0.44 & 0 & 0.24 & 0.05 & 0.01 & 0.002 & 0.69 & 0.052 \\
\hline & Wet & Total input & 1.62 & 0 & 0.53 & 0 & 0.22 & 0.544 & 2.37 & 0.544 \\
\hline & Season & Total output & 1.54 & 0 & 0.18 & 0 & 0.18 & 0.45 & 1.9 & 0.45 \\
\hline & & Storage & 0.08 & 0 & 0.35 & 0 & 0.04 & 0.094 & 0.47 & 0.094 \\
\hline \multirow{6}{*}{$\begin{array}{l}\text { Dry } \\
\text { Year }\end{array}$} & Dry & Total input & 0.37 & 1.28 & 0.44 & 0.22 & 0.012 & 0.312 & 0.822 & 1.812 \\
\hline & Season & Total output & 0.32 & 1.1 & 0.14 & 0.17 & 0.009 & 0.3 & 0.469 & 1.57 \\
\hline & & Storage & 0.05 & 0.18 & 0.3 & 0.05 & 0.003 & 0.012 & 0.353 & 0.242 \\
\hline & Wet & Total input & 1.37 & 0 & 0.43 & 0 & 0.11 & 0.38 & 1.91 & 0.38 \\
\hline & Season & Total output & 1.23 & 0 & 0.17 & 0 & 0.06 & 0.34 & 1.46 & 0.34 \\
\hline & & Storage & 0.14 & 0 & 0.26 & 0 & 0.05 & 0.04 & 0.45 & 0.04 \\
\hline
\end{tabular}

Classification of the estuaries in the estuarine systems is:

EES - Lower Meghna, Tetulia, Lohalia

CES - Bishkhali, Baleshwar, Burishwar

WES - Estuarine systems of the Sundarban

Freshwater input from the freshwater zone - Gorai, Arial Khan, Lower Meghna
Freshwater input from the saltwater zone - Intersect channels at the threshold isohaline

Saltwater input from the freshwater zone - Intersect channels at the threshold isohaline

Saltwater input from the saltwater zone - Extreme seaward boundaries of the channels 
Cross channel flows between EES \& CES - 3 spill channels and the Beel Route

Cross channel flows between CES \& WES - Madhumati and Ghashiakhali channels

Based on the above classification of channels input, output and storage are calculated and are shown in Table I and Table II. In Table I and Table II, FWZ stands for freshwater zone and SWZ stands for saltwater zone. From Table I and Table II, it can be said that total freshwater input in the estuarine systems of the GBM delta varies between 2.73-4.17 trillion $\mathrm{m}^{3}$. Out of this total volume 1.91-2.37 trillion $\mathrm{m}^{3}$ of water comes into the system during monsoon and the rest $0.82-1.80$ trillion $\mathrm{m}^{3}$ of water comes during the dry period.

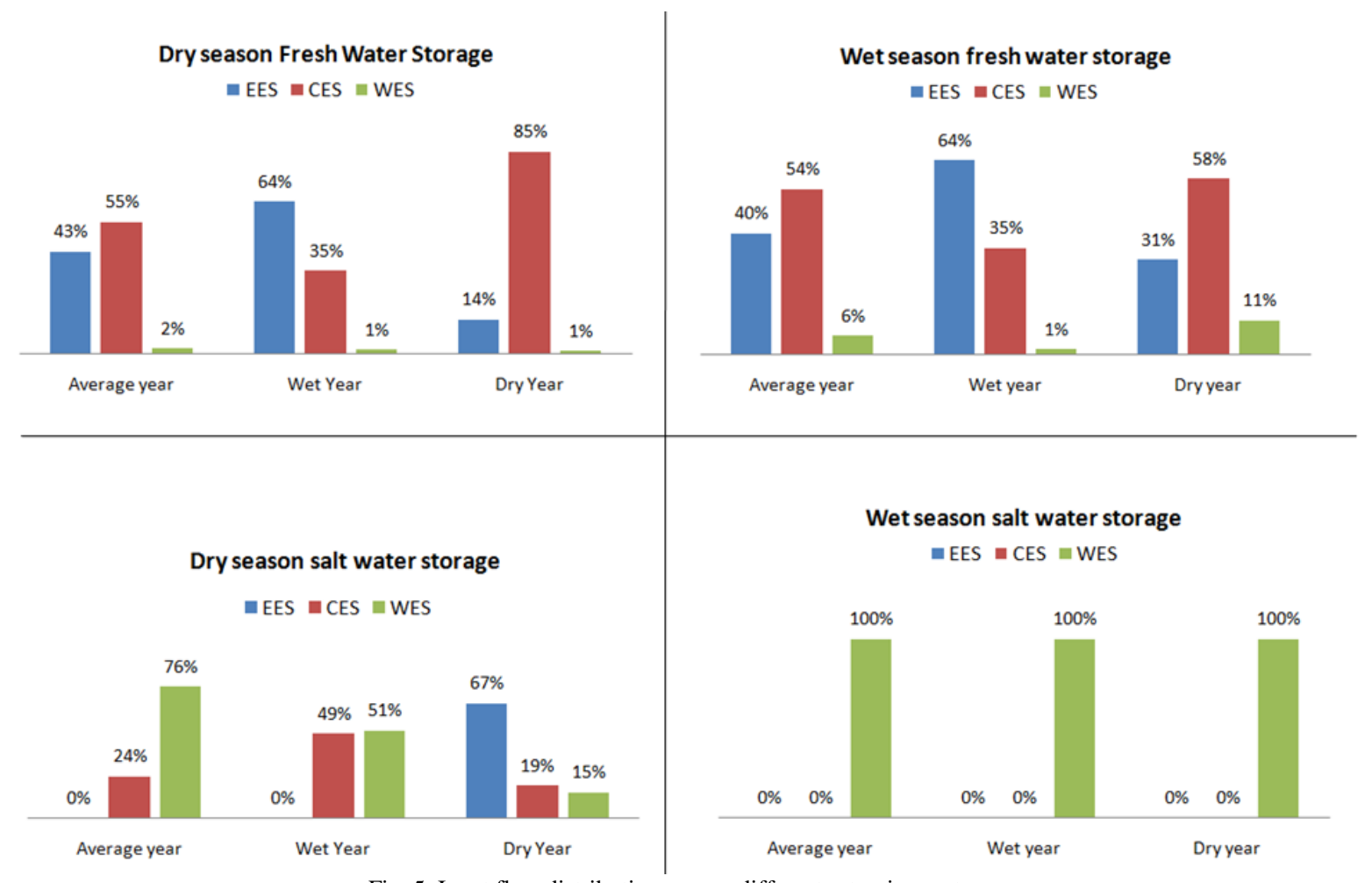

Fig. 5. Input flow distribution among different estuarine systems.

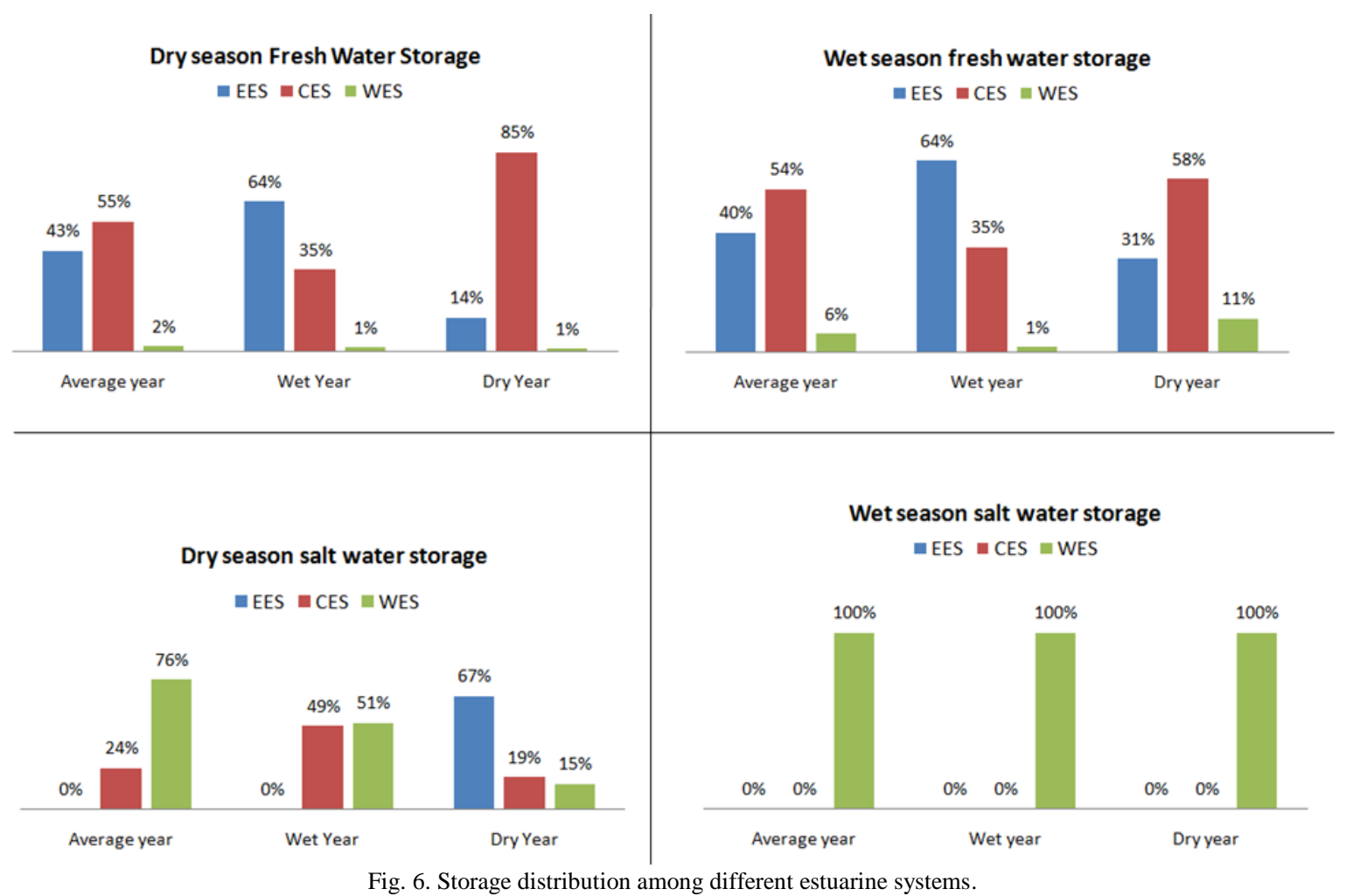

Total amount of saltwater inflow into the system is much less and it varies between 0.93-2.19 trillion $\mathrm{m}^{3}$. Saltwater intrusion during monsoon varies between $0.38-0.54$ trillion $\mathrm{m}^{3}$ and during dry season the amount is between $0.30-1.81$ trillion $\mathrm{m}^{3}$. So, saltwater intrusion is much higher during the dry season than during the monsoon. 
Storage in the system is the amount of water retained after the water goes out from the system. Total freshwater storage in the system varies between $0.80-1.16$ trillion $\mathrm{m}^{3}$. Within this volume of storage, dry season storage varies between $0.35-0.69$ trillion $\mathrm{m}^{3}$ and the monsoon storage varies between $0.45-0.68$ trillion $\mathrm{m}^{3}$. Saltwater storage, on the other hand, is much less than the freshwater storage and the total amount of saltwater storage varies between $0.15-0.28$ trillion $\mathrm{m}^{3}$. Dry season saltwater storage is higher than the monsoon. In dry season, saltwater storage varies between $0.05-0.24$ trillion $\mathrm{m}^{3}$ and during monsoon, the amount drops down to $0.04-0.13$ trillion $\mathrm{m}^{3}$.

\section{INFLOW DISTRIBUTION}

Based on Table I, Fig. 5 is prepared that shows input flow distribution among different estuarine systems. The seasonality and the flooding condition are abbreviated as:

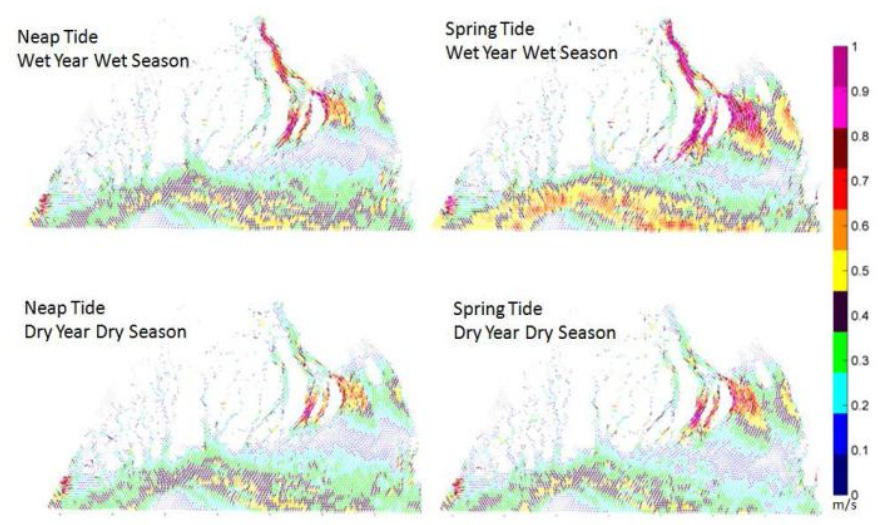

Fig. 7. Estuarine circulation patterns at neap \& spring tides during extreme wet and dry conditions.

Dry season Dry year - DD

Dry season Wet year - DW

Dry season Average year - DA

Wet season Dry year - WD

Wet season Wet year - WW

Wet season Average year - WA

Fig. 5 shows that regardless of seasonality, EES receives the maximum amount of freshwater flow, except in extreme dry condition, DD. In DW, EES receives the maximum flow among the three systems ( $80 \%$ of the total). The amount drops to $45 \%$ in a DD when intake of CES is the maximum. Freshwater inflow into the WES is always very small compared to the other two systems. In WW, it reaches the maximum (9\%) and in DD, it is the minimum (1\%). In critical dry season (DD), CES receives the maximum amount of freshwater flow (54\%), even in higher percentage than the EES (45\%). This shows importance of CES in critical dry season. On the other hand in WW, when water is supposed to be abundant, share of CES drops to $22 \%$ with the increase of EES share to $68 \%$.

When we look into the saltwater inflow, the wet season scenarios, regardless of the flooding conditions, show that the Saltwater is entering only from the WES inlets $(100 \%$ in all wet season scenarios). This means that whatever saltwater enters into the system in wet seasons, it enters through the WES. This is mainly due to very low freshwater inflow of
WES during this time (6\% to $9 \%$ ) compare to the other two systems. The situation for WES improves in critical dry season DD, when share of WES drops to $17 \%$ and the share of EES increases to $71 \%$ regarding saltwater intrusion.

\section{StORAGE DistribUtion}

Fig. 6 shows the storage distribution in different seasons and in different flooding conditions. When freshwater storage is considered, in most of the seasons and in most of the flooding conditions CES contains the maximum storage. In critical dry period of DD and also in WD, the share of CES is the maximum among the three systems (85\% and 58\% respectively). When water is abundant in WW, the EES contains the maximum amount of storage. WES always has very low freshwater storage and the share varies from $1 \%$ (in DD and WW) to $11 \%$ (in WD). Even when water is abundant in the entire system during WW, WES has only $1 \%$ share of the freshwater.

Saltwater storage scenario is just the reverse of freshwater storage scenario. In this case, during wet seasons of all the flooding conditions, WES stores the entire saltwater of the systems (100\%). Share of WES decreases in dry season, but still the amount is significant (varies from $15 \%$ to $76 \%$ ). In terms of saltwater storage, share of EES is generally low, except during DD (67\%). On the other hand, CES always shares some percentage of saltwater during dry season (share varies from $19 \%$ to $49 \%$ ).

\section{ROLE OF CES IN CRITICAL DRY PERIOD}

The inflow and storage distribution shown in Table I and Table II and in Fig. 5 and Fig. 6 shows, in general, EES receives the maximum amount of freshwater flow, except in critical dry period, when CES takes the lead. When the scenario changes from WW to DD, the roles of EES and CES also change. The share of EES decreases from $68 \%$ to $45 \%$ whereas, the share of CES increases from $22 \%$ to $54 \%$. The inflow scenario is also reflected in the storage scenario. During DD, bulk of the share of freshwater storage is carried by CES which amounts to $85 \%$ among the three systems, when EES carries only $14 \%$. This shows importance of CES during the critical dry period. As shown in Fig. 1, the main inflow of CES comes from the Arial Khan intake, and the Arial Khan is bifurcated from the Padma River, which carries the combined flow of the Ganges and the Brahmaputra. During DD, Ganges carries very low flow [16]. So, the inflow comes to CES through the Arial Khan basically comes from the Brahmaputra. So, we can say that in the critical dry period Brahmaputra plays a significant role as a source of freshwater flow in the GBM estuarine systems. In critical dry period, decrease of flow in the Brahmaputra due to climate change or any other intervention will significantly affect the water availability in the entire south west region of Bangladesh.

\section{IMPACT OF FLOW DISTRIBUTION PATTERNS ON DELTA DYNAMICS AND ESTUARINE ENVIRONMENT}

An essential component of delta dynamics is the source of sediment. Although this study does not explicitly examine 
sediment discharges, it is nevertheless the case that there is a strong relationship between flow and sediment transport. As such, the flow distribution can be treated as a useful proxy variable for analyzing the likely partitioning of sediment flows through the delta system.

To analyze the impact of flow distribution pattern and the delta dynamics, the Delft 3D model is applied in the study region to compute the estuarine circulation patterns and tidal excursion. Computed estuarine circulation pattern for the estuaries of the GBM delta is shown in Fig. 7.

Fig. 7 shows that Lower Meghna estuary is the most dominant channel in the system. During different flooding conditions and tidal instants, high velocity flows (velocity in the order of more than $1 \mathrm{~m} / \mathrm{s}$ ) comes down from the Lower Meghna. This flow interacts with relatively low velocity flow (in the order of $0.5 \mathrm{~m} / \mathrm{s}$ ) from the sea and the resultant flow, in general, is directed towards the land through the WES outlet. The residual flow circulation pattern over a hydrological year is shown in Fig. 8.

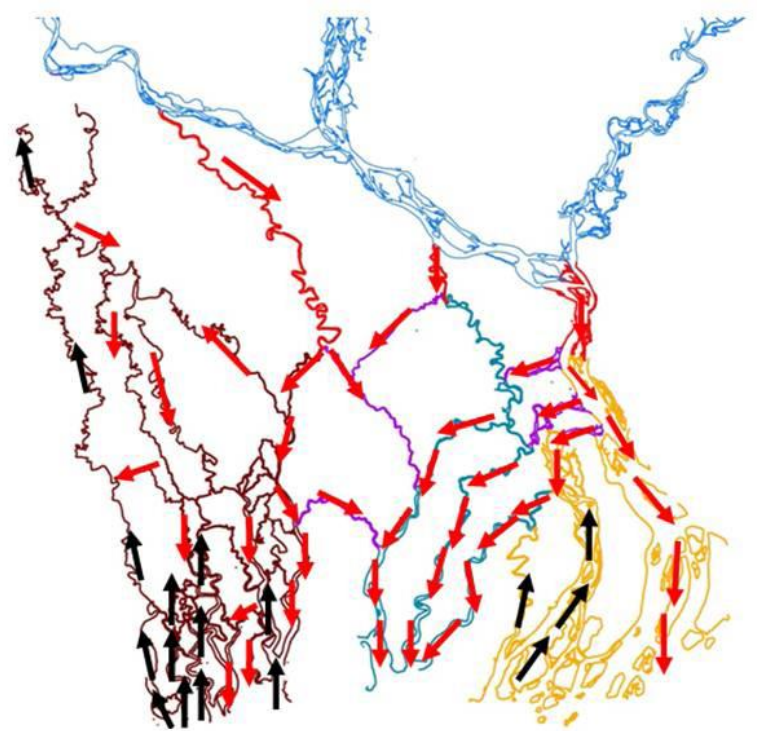

Fig. 8. Residual flow circulation pattern in the estuarine systems of the GBM delta.

Fig. 8 shows that the Lower Meghna estuary is a predominantly ebb-dominated channel. The rest of the channels of the EES are flood-dominated. For the CES, all the channels are ebb-dominated and for the WES, the channels are flood dominated. These systems have created two clockwise-rotating estuarine circulation patterns. In one system the Lower Meghna and the associated channels of EES makes a clockwise circulation. The other system is the main circulation system that consists of all the three estuarine systems. The flows come down from the Lower Meghna and the CES systems, turn clockwise, and re-enter into WES systems. This type of clockwise residual circulation also found elsewhere [7].

To compute the extent of travel of an individual sediment particle, tidal excursion is computed and is shown in Fig. 9 for different seasons and for different flooding conditions. The tidal excursion is computed as:

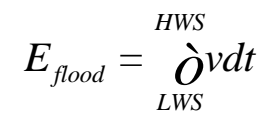

$$
E_{e b b}=\stackrel{L W S}{\grave{O}} v d t
$$

where $E_{\text {flood }}$ is the tidal excursion during flood tide and $E_{e b b}$ is the tidal excursion during the ebb tide, HWS is the high water slack time and LWS is the low water slack time and $\mathrm{v}$ is the instantaneous tidal velocity. Fig. 9 shows that from Lower Meghna Estuary and from CES system, a sediment particle will move into the sea with the ebb tide, and with the estuarine circulation mentioned above, will re-enter into the WES system during the flood tide.
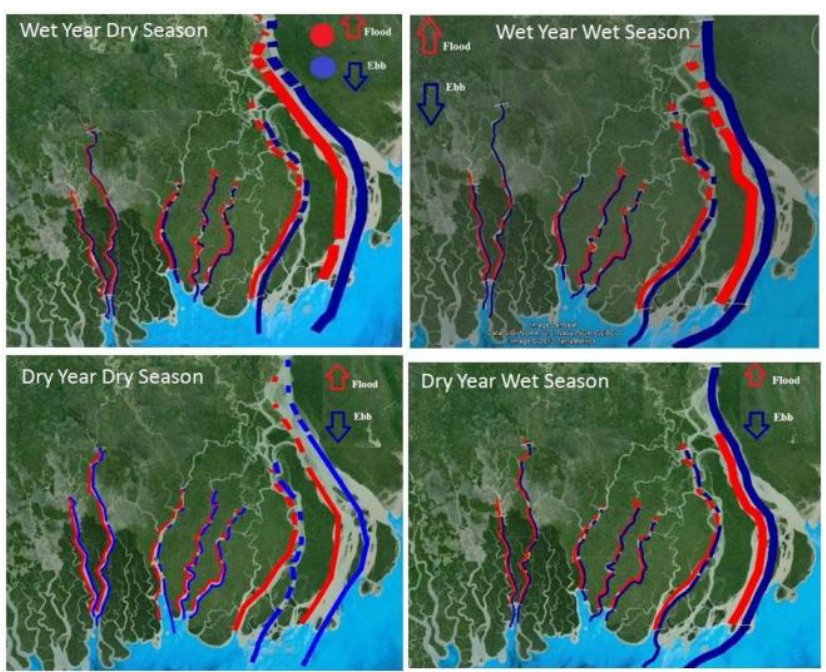

Fig. 9. Tidal excursion.

Analyzing the flow distribution and arrangements of the estuarine systems of the GBM delta, it is obvious that the Meghna estuary is likely to be the main conduit for sediment. As this system is largely ebb dominated (Fig. 7-Fig. 9), the high tidal excursion during the ebb will drain the incoming sediments to the Bay of Bengal through the mouth of the Meghna estuary. A clockwise residual circulation in the Bay of Bengal near the mouth of the estuaries particularly during the monsoon (Fig. 8) may drive these sediments in the western direction. With the relatively low freshwater flow contribution of the WES (Table I and Fig. 5), these sediments may be directed towards the mouth of the estuaries of the WES. As most of the estuaries of WES can be considered as flood dominated (Fig. 8 and Fig. 9), these sediments will re-enter into WES system. The WES contains the estuaries that feed the Sundarban. Considering this mechanism, and remembering the fact that the freshwater inflow of WES is the lowest of the three systems (Table I and Fig. 5), the sediment feed of this system from the upstream sources (mainly Ganges) must be very low. So, the estuarine systems contributing to the Sudarbans are receiving sediments only from these re-entered sources from the Bay of Bengal. This mechanism is playing a significant role in the delta dynamics of the GBM delta [17].

It is obvious from Fig. 5 and Fig. 6 that out of the three estuarine systems, the freshwater inflow and storages of EES is the maximum among the three. On the other hand, saltwater inflow and storage is dominantly large in WES system. The inflow and storage of CES is occasionally dominated by either freshwater or saltwater. As a result, in most of the time in a year, the estuarine environment of EES is 'fresh' while that 
for WES is 'salty'. The environment for CES is mixed and it varied from fresh to salt depending on the flooding scenario and seasonality. Sediments in the western system are mainly cohesive sediments ranging from silt to clay [18]. Salty environment of WES makes the re-entered sediments from the sea to form flocks and results sedimentation in the region.

The sediments in these estuarine systems are mainly coming through the Brahmaputra and the Ganges rivers during the monsoon [17]. Like water flow, the Brahmaputra sediment is mixed with the Ganges sediment and the combined sediments are discharged through the estuarine systems of the GBM delta to the Bay of Bengal. Most of these sediments flow through the Lower Meghna estuary and through estuaries of CES system to the Bay of Bengal. As described above, part of these sediments may re-enter into WES. The dominant contributor of freshwater flow for the EES is the Lower Meghna estuary, for the CES is the Brahmaputra River and for the WES is the Ganges River. The Lower Meghna estuary carries the combined discharge of the Ganges, the Brahmaputra and the Upper Meghna. So, the sediment of the Lower Meghna estuary is the combined sediments from these major river systems. The upstream sediment source of the CES is basically from the Brahmaputra River, whereas, for WES, it is the Ganges River. As most of the sediments are carried during the monsoon and EES receives the maximum amount of share among the three systems (Fig. 5), the EES will carry the bulk of the sediments coming from the major river systems of the GBM delta during monsoon. On the other hand, the share of CES increases during the dry period (Fig. 5 and Fig. 6). So, it is expected that, whatever sediments are coming to the system during the dry period, CES carries a significant part of it, specially, the sediments contributed by the Brahmaputra river. These features dictate the nature of estuarine environment of the GBM delta.

\section{CONCLUSION}

The main conclusions from the study are:

1) Total freshwater and saltwater inputs in the estuarine systems of the GBM delta vary between $2.73-4.17$ trillion $\mathrm{m}^{3}$ and $0.93-2.19$ trillion $\mathrm{m}^{3}$ respectively.

2) Total freshwater and saltwater storages in the estuarine systems of the GBM delta vary between $0.80-1.16$ trillion $\mathrm{m}^{3}$ and $0.15-0.28$ trillion $\mathrm{m}^{3}$ respectively.

3) Freshwater share is the maximum for the eastern system during monsoon and for the central system during dry season, whereas the western system carries bulk of the saltwater throughout the year.

4) In critical dry period, decrease of Brahmaputra flow will adversely affect the entire south-west region of Bangladesh.

5) Lower Meghna estuary is the main channel carrying sediments in the region during monsoon and estuaries of the central estuarine system carry sediments during dry season. Large tidal excursion during ebb tide brings this sediment to the sea. Clock-wise estuarine circulation and flood dominance of western channels makes these sediments to re-enter into the western estuarine system where ecologically important Sundarban is located.
6) Water in western system is saline and sediments coming are mainly silt and clay. So, the saline environment accelerates the rate of sedimentation in the region.

\section{REFERENCES}

[1] M. R. Islam, S. F. Begum, Y. Yamaguchi, and K. Ogawa, "The ganges and brahmaputra rivers in Bangladesh: Basin denudation and sedimentation," Hydrol. Process, vol. 13, pp. 2907-2923, December 1999.

[2] S. N. Islam, "Threatened wetlands and ecologically sensitive ecosystem management in Bangladesh," Front. Earth Sci., vol. 4, no. 4, pp. 438-448, 2010.

[3] M. Rahman, A. Haque, M. K. B. Siddique et al., "A preliminary assessment of the impact of fluvio-tidal regime on Ganges-Brahmaputra-Meghna delta and its impact on the ecosystem resources," in Proc. the International Conference on Climate Change Impact and Adaptation (I3CIA-2013), Center for Climate Change and Sustainability Research (3CSR), Department of Civil Engineering, DUET, Gazipur, Bangladesh, December 2013.

[4] J. U. Chowdhury and A. Haque, "Numerical simulation of tides and saline water intrusion in the Meghna delta," Dhaka, Bangladesh, 1988.

[5] S. Islam and J. U. Chowdhury, "Hydrological characteristics of the 1998 Flood in major rivers," Engineering Concerns of Flood, BUET: Dhaka, Bangladesh, 2002, pp. 227-239.

[6] MES, Hydro-Morphological Dynamics of the Meghna Estuary, DHV Consultants BV, Dhaka, Bangladesh, 2001.

[7] M. A. Hussain, M. A. Hossain, and A. Haque, "Seasonal variation of residual currents in the Meghna estuary of Bangladesh," Coastal Dynamics, no. 30, 2009.

[8] HEC, HEC RAS river analysis system, User's Manual, Version 4.1; US Army Corps of Engineers: Hydraulic Engineering Center, USA, 2010.

[9] D. Mahapatro, D. R. C. Panigrahy, S. Naik, S. K. Pati, and R. N. Samal, "Macro benthos of shelf zone off dhamara estuary, bay of Bengal," Journal of Oceanography and Marine Science, vol. 2, no. 2, pp. 32-42, February 2011.

[10] T. G. Trucano, L. P. Swiler, T. Igusa, W. L. Oberkampf, and M. Pilch, "Calibration, validation, and sensitivity analysis: What's what," Reliability Engineering and System Safety, vol. 91, pp. 1331-1357, 2006.

[11] BWDB, Annual Flood Report, Flood Forecasting and Warning Centre, Processing and Flood Forecasting Circle, Bangladesh Water Development Board, Dhaka, Bangladesh, 2012.

[12] A. Haque, Sumaiya, M. Salehin, M. Rahman, and S. Alam, "Reliability analysis of dynamic models," 2014.

[13] BARC, Agricultural Technologies for the Southwest Region of Bangladesh. Bangladesh Agricultural Research Council, 2013, pp. 14.

[14] M. Hossain, S. Saha, S. Salekin, A. Al-Mamun, M. R. H. Siddique, and S. M. R. Abdullah, "Salinity influence on germination of four important mangrove species of the Sundarban, Bangladesh," Agriculture and Forestry, vol. 60, issue 2, pp. 125-135, 2014.

[15] M. A. R. Hossain, M. A. Wahab, and B. Belton, The Checklist of the Riverine Fishes of Bangladesh. Fan-Bangladesh, pp. 29-39, 2012

[16] A. K. Gain and C. Giupponi, "Impact of the farakka dam on thresholds of the hydrologic flow regime in the lower ganges river basin (Bangladesh)," Water, vol. 6, pp. 2501-2518, 2014.

[17] K. G. Rogers, S. L. Goodbred, and D. R. Mondal, "Monsoon Sedimentation on the abandoned tide influenced Ganges-Brahmaputra delta plain. Estuarine," Coastal and Shelf Science, vol. 131, pp. 297-309, 2013.

[18] K. Rajkumar, A. L. Ramanathan, and P. N. Bethera, "Characterization of clay minerals in the sundarban mangroves river sediments by SEM/EDS," Journal Geological Society of India, vol. 80, pp. 429-434, September 2012.

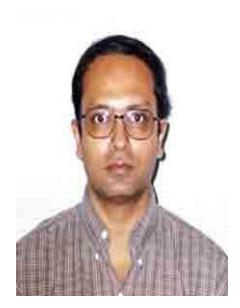

Anisul Haque was born in Khulna, Bangladesh on June 2, 1962. He received his PhD degree from the Department of Civil Engineering, K.U. Leuven, Belgium, in February 1994. His major fields of interests are in marine and estuarine processes, delta dynamics, flow and transport processes, computational fluid dynamics, numerical techniques and modeling, basic hydraulics.

$\mathrm{He}$ is the professor at the Institute of Water and 
Flood Management (IWFM), Bangladesh University of Engineering and Technology (BUET), Dhaka, Bangladesh.

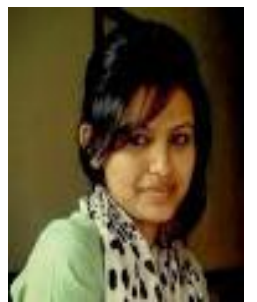

Sumaiya was born in Kishoregonj, Bangladesh on October 30, 1989. She received her B.Sc. degree from the Department of Civil and Environmental Engineering, Shahjalal University of Science and Technology, Sylhet, Bangladesh, in 2011. Her major fields of interests are in marine and estuarine processes, delta dynamics, flow and transport processes, computational fluid dynamics, numerical techniques and modeling, basic hydraulics.

She is the M.Sc. student of Institute of Water and Flood Management (IWFM), Bangladesh University of Engineering and Technology (BUET), Dhaka, Bangladesh. Also, she is working as a research associate in the ESPA Project.

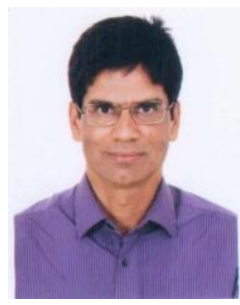

Munsur Rahman was born in Rajshahi, Bangladesh on December 27, 1965. He received his $\mathrm{PhD}$ degree from the Graduate School of Civil Engineering, Kyoto University, Japan, in 1999. During his 24-year professional career, Prof Munsur focuses his research on the formation processes of large-scale sand bars in tidal and non-tidal rivers, together with the growth of char land resources and livelihood strategy of the people living there. During 2007 to
2009, he executed a collaborative research with Vietnam, Cambodia and UK funded by DelPHE on the issue of river erosion bank protection and social response. Recently, he has started a 4-year-long consortium grant project with UK, Indian, and Chinese partners on the theme of health, livelihood, ecosystem services and poverty alleviation in populous deltas. The results will be useful in managing the populous deltas in a sustainable manner. His general research interests are grouped into river and coastal processes, morphodynamics, river and coastal management, ecosystem services of river, coasts and floodplain system, indigenous approach on river, coasts and floodplain management, bridge hydraulics and related problems.

$\mathrm{He}$ is the professor at the Institute of Water and Flood Management (IWFM), Bangladesh University of Engineering and Technology (BUET), Dhaka, Bangladesh. 